\title{
SISTEM PAKAR UNTUK MENDIAGNOSA KERUSAKAN PERANGKAT TELEVISI MENGGUNAKAN METODE BACKWARD CHAINING
}

\author{
Deny Wiria Nugraha ${ }^{1}$ \\ deny_wiria_nugraha@yahoo.co.id
}

\begin{abstract}
This study aims to design and build an expert system that can diagnose damage to the television set based on the type and characteristics of the damage by using backward chaining method. The expert system in this study has been designed and built using the backward chaining method. It starts by proving the preliminary conclusions based on direct observations of users of the damage type to the television set that will be repaired, and the results show the facts and the rules appropriate to the type and characteristics of the damage to the television set. The expert system was proved capable of receiving, storing, and transferring knowledge from experts or repair technicians of the damage to the television set according to the type and characteristics of the actual damage to the television set. This expert system also proved to be able to function properly to diagnose problem of the television set based on the type and characteristics of the damage.
\end{abstract}

Keywords : expert system, television set, backward chaining

\section{Pendahuluan}

Pada saat ini, perangkat televisi adalah salah satu media favorit bagi masyarakat. Hampir di setiap rumah, kantor/instansi, dan perusahaan dapat dijumpai media informasi ini. Melalui perangkat televisi, masyarakat bisa mendapatkan informasi yang diperlukan baik untuk kepentingan pekerjaan maupun sebagai sarana hiburan. Kenyataan ini tidak lepas dari kreatifitas dan loyalitas pihak pengelola stasiun televisi untuk menyajikan siaran-siaran yang berkualitas dan bermanfaat bagi masyarakat.

Sebagai peralatan elektronika, perangkat televisi tentu saja akan mengalami gangguan atau kerusakan. Hal ini akan sangat mengganggu pengguna televisi karena jika hal itu terjadi, maka program siaran televisi yang disukai akan terlewatkan tanpa bisa ditonton.

Usaha di bidang perbaikan peralatan elektronika memiliki teknisi-teknisi yang dapat membantu para pengguna peralatan elektronika khususnya perangkat televisi dengan menawarkan jasa perbaikan. Di tempat jasa perbaikan tersebut, memiliki teknisi elektronika khususnya teknisi perbaikan kerusakan perangkat televisi yang sudah berpengalaman (teknisi senior) dan teknisi yang baru belajar (teknisi pemula). Bagi teknisi pemula, dalam memperbaiki kerusakan peralatan elektronika khususnya perangkat televisi seringkali harus meminta petunjuk dari teknisi senior, karena bagi mereka memperbaiki kerusakan peralatan elektronika ini tingkatannya cukup sulit sehingga membuat proses perbaikan membutuhkan waktu yang cukup lama. Kesulitan lain yang biasa dialami oleh teknisi pemula adalah apabila teknisi senior yang bisa memberikan petunjuk sedang tidak berada di tempat atau sedang sibuk dengan pekerjaannya.

\footnotetext{
${ }^{1}$ Program Studi Teknik Informatika, Jurusan Teknik Elektro, Fakultas Teknik, Universitas Tadulako
} 
Dari pengetahuan dan pengalaman yang dimiliki oleh teknisi senior, membuat teknisi senior tersebut mampu dengan cepat mengetahui penyebab kerusakan peralatan elektronika, misalnya perangkat televisi berdasarkan jenis kerusakan yang ada. Kemampuan ini bisa diterapkan dalam bentuk perangkat lunak komputer. Bagian ilmu komputer yang mempelajari cara berpikir seorang pakar dalam menyelesaikan masalah dengan mengambil kesimpulan dari fakta yang ada kemudian diterapkan dalam bentuk perangkat lunak komputer adalah Sistem Pakar (Expert System). Sistem pakar adalah cabang dari Kecerdasan Buatan (Artificial Intelligence), yaitu bidang ilmu yang mempelajari bagaimana membuat mesin (komputer) mampu melakukan sesuatu hal sebaik yang dilakukan oleh manusia.

Rumusan masalah dalam penelitian ini adalah bagaimana cara merancang dan membangun perangkat lunak komputer berupa sistem pakar untuk mendiagnosa kerusakan perangkat televisi dengan cara memindahkan kepakaran/pengetahuan teknisi elektronika khususnya teknisi perbaikan kerusakan perangkat televisi ke dalam sebuah perangkat lunak komputer menggunakan metode backward chaining. Tujuan dari penelitian ini adalah merancang dan membangun sistem pakar yang dapat mendiagnosa kerusakan pada perangkat televisi berdasarkan jenis dan ciri kerusakan yang ada dengan menggunakan metode backward chaining.

\section{Tinjauan Pustaka}

Beberapa penelitian sebelumnya yang peneliti jadikan pendukung dalam penelitian ini adalah sebagai berikut:

a. Penelitian Firmansyah (2009), Sistem Pakar Diagnosis Kerusakan Pada Televisi Berwarna. Tujuan penelitian tersebut adalah memudahkan para teknisi khususnya teknisi junior dalam mendiagnosa kerusakan pada televisi berwarna. Perbedaan penelitian ini dengan penelitian Firmansyah (2009) adalah penelitian tersebut menggunakan metode forward chaining dan aplikasi sistem pakar dibuat menggunakan bahasa pemrograman Microsoft Visual Basic 6.0, serta pembuatan sistem pakar tersebut hanya menyangkut kerusakan-kerusakan yang umum terjadi pada televisi berwarna, diantaranya kerusakan pada bagian gambar, suara, dan catu daya.

b. Penelitian Setiawan (2011), Sistem Pakar Diagnosis Kerusakan Pada Televisi Berwarna. Manfaat dalam penelitian tersebut adalah mempermudah para teknisi muda untuk mendiagnosa kerusakan televisi dan memberikan saran-saran bagi pengguna umum yang ingin memperbaiki televisinya. Perbedaan penelitian ini dengan penelitian Setiawan (2011) adalah penelitian tersebut menggunakan bahasa pemrograman Microsoft Visual Basic 6.0, aplikasi tersebut dibangun dengan metode forward chaining dan aplikasi tersebut terbatas hanya untuk pesawat televisi berwarna berjenis CRT (Chatode Ray Tube).

c. Penelitian Lumbantobing (2011), Aplikasi Sistem Pakar Diagnosis Kerusakan Pada Televisi Berwarna. Penelitian tersebut merupakan suatu sistem pakar yang dirancang sebagai alat bantu untuk mendiagnosis jenis kerusakan televisi berwarna dengan basis pengetahuan yang dinamis. Penelitian Lumbantobing (2011) menggunakan Microsoft Visual Basic 6.0 dan penarikan kesimpulan dalam sistem pakar tersebut menggunakan metode inferensi forward chaining. Sistem pakar tersebut akan menampilkan pilihan gejala yang dapat dipilih user, dimana setiap pilihan gejala akan membawa user kepada pilihan gejala selanjutnya sampai mendapatkan hasil akhir.

d. Penelitian Rapu (2012), Sistem Pakar Diagnosa Kerusakan Pesawat Televisi Berwarna dengan Menggunakan Metode Forward Chaining. Penelitian tersebut merancang dan membuat aplikasi sistem pakar untuk diagnosa kerusakan pada pesawat televisi berwarna dan hanya menyangkut kerusakan-kerusakan yang umum diantaranya kerusakan pada bagian gambar, suara, dan catu daya. Pembuatan aplikasi pada penelitian tersebut menggunakan bahasa pemrograman Delphi 7.0 dan database Microsoft Office Access 2007.

e. Penelitian Perwira dan Azis (2013), Sistem Pakar Untuk Mendiagnosa Penyakit Infeksi TBC Paru. Penelitian tersebut bertujuan untuk melakukan rancang bangun sistem pakar untuk mendiagnosa penyakit infeksi TBC paru dan merancang sistem pakar yang mampu memberikan saran berdasarkan gejala yang diinputkan user. Penelitian Perwira dan Azis 
(2013) menggunakan bahasa pemrograman Delphi 7, menggunakan metode forward chaining, dan basis pengetahuannya dapat direpresentasikan dengan kaidah produksi berdasarkan nama penyakit, gejala-gejala serta saran pengobatan.

Kelima penelitian sebelumnya diatas, semuanya berkonsentrasi dalam membuat sebuah sistem pakar yang merupakan salah satu bidang ilmu Artificial Intelligence (AI) atau kecerdasan buatan. Artificial Intelligence (AI) atau kecerdasan buatan merupakan cabang dari ilmu komputer yang konsern dengan pengautomatisasi tingkah laku cerdas (Desiani dan Arhami, 2006:1). Ilmu komputer tersebut mengembangkan perangkat lunak dan perangkat keras untuk menirukan tindakan manusia. Aktivitas manusia yang ditirukan seperti penalaran, penglihatan, pembelajaran, pemecahan masalah, pemahaman bahasa alami, dan sebagainya. Teknologi kecerdasan buatan dipelajari dalam bidang-bidang seperti: Robotika (Robotics), Penglihatan Komputer (Computer Vision), Pengolahan Bahasa Alami (Natural Language Processing), Pengenalan Pola (Pattern Recognition), Sistem Syaraf Buatan (Artificial Neural System), Pengenalan Suara (Speech Recognition), dan Sistem Pakar (Expert System).

Sistem pakar adalah sistem berbasis komputer yang menggunakan pengetahuan, fakta, dan teknik penalaran dalam memecahkan masalah yang biasanya hanya dapat dipecahkan oleh seorang pakar dalam bidang tersebut (Martin dan Oxman, dalam Kusrini:2006:11).

Sistem pakar merupakan satu istilah yang digunakan pada sebuah teknik pintar yang sangat bergantung pada kepakaran manusia baik secara langsung maupun tidak langsung (Priyono dan Rahmat, 2013:32).

Sebuah sistem pakar mempunyai kemampuan berdialog dengan pemakai dan kemudian memberikan suatu saran, pandangan, atau kesimpulan (Kadir, 2014:117).

Pada dasarnya sistem pakar diterapkan untuk mendukung aktivitas pemecahan masalah. Beberapa aktivitas pemecahan yang dimaksud antara lain: pembuatan keputusan (decision making), pemaduan pengetahuan (knowledge fusing), pembuatan desain (designing), perencanaan (planning), prakiraan (forecasting), pengaturan (regulating), pengendalian (controlling), diagnosis (diagnosing), perumusan (prescribing), penjelasan (explaining), pemberian nasehat (advising), dan pelatihan (tutoring).

Untuk membangun sistem pakar maka komponen-komponen yang harus dimiliki adalah sebagai berikut (Giarratano dan Riley, dalam Hartati dan Iswanti, 2008:3-4):
a. Antarmuka pengguna (user interface).
b. Basis pengetahuan (knowledge base).
c. Mekanisme inferensi (inference machine).
d. Memory kerja (working memory).

Sedangkan untuk menjadikan sistem pakar menjadi lebih menyerupai seorang pakar yang berinteraksi dengan pemakai, maka dilengkapi dengan fasilitas sebagai berikut:

a. Fasilitas penjelasan (explanation facility).

b. Fasilitas akuisisi pengetahuan (knowledge acquisition facility).

Struktur sistem pakar dapat dilihat pada gambar 1.

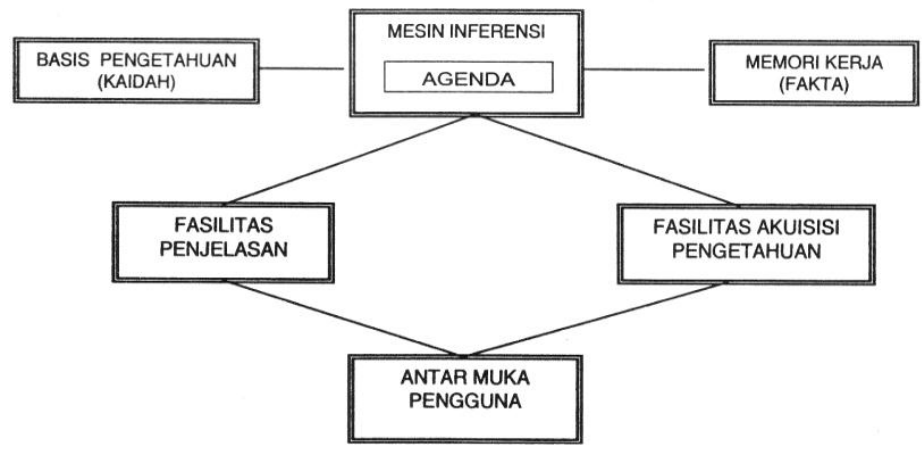

Gambar 1. Struktur sistem pakar

(Sumber: Hartati dan Iswanti, 2008:4) 
Kelima penelitian sebelumnya yang telah dijelaskan diatas yaitu penelitian Firmansyah (2009), Setiawan (2011), Lumbantobing (2011), Rapu (2012), dan Perwira dan Azis (2013), semuanya menggunakan metode forward chaining sebagai metode inferensinya. Sedangkan penelitian ini menggunakan metode bacward chaining sebagai metode inferensinya. Ada dua metode inferensi yang penting dalam sistem pakar, yaitu forward chaining dan backward chaining.

\section{a. Forward Chaining}

Forward chaining dilakukan mulai dari kalimat-kalimat yang ada dalam knowledge base dan membangkitkan kesimpulan-kesimpulan baru sehingga dapat digunakan untuk melakukan inferensi yang lebih jauh (Suyanto, 2014:90). Forward chaining biasanya digunakan ketika suatu fakta baru ditambahkan ke dalam knowledge base dan ingin membangkitkan konsekuensi logisnya.

Pencocokan fakta atau pernyataan dimulai dari bagian kiri (IF). Dengan kata lain, penalaran dimulai dengan fakta yang ada pada bagian premis aturan IF [fakta] THEN [kesimpulan]. Untuk menguji kebenaran hipotesis, dari fakta-fakta tersebut selanjutnya akan ditentukan kesimpulan yang terletak pada sebelah kanan aturan IF [fakta] THEN [kesimpulan]. Metode ini dapat dilihat pada gambar 2 .

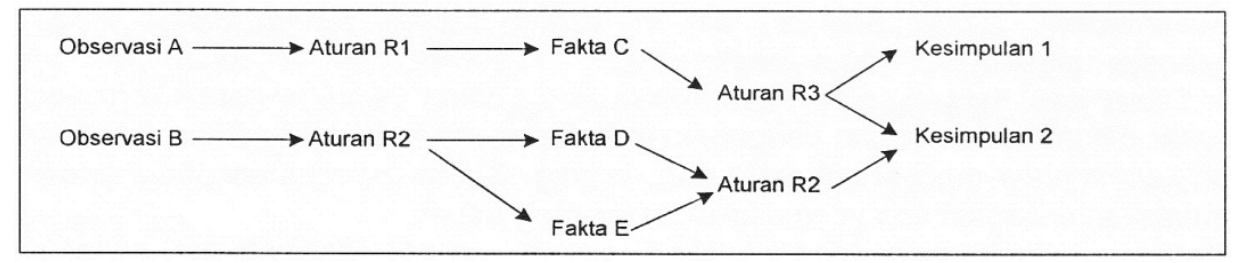

Gambar 2. Metode forward chaining

(Sumber: Perwira dan Azis, 2013:66)

\section{b. Backward Chaining}

Bacward chaining dimulai dari sesuatu yang ingin dibuktikan, kemudian mencari kalimatkalimat implikasi sehingga dapat membuat kesimpulan sampai menemukan premis yang ingin dibuktikan. Tentu saja, bacward chaining hanya dapat digunakan jika ada goal yang ingin dibuktikan (Suyanto, 2014:90).

Pencocokan fakta atau pernyataan dimulai dari bagian kanan (THEN). Dalam pendekatan ini pelacakan dimulai dari informasi masukan yaitu data tujuan dari aturan IF [fakta] THEN [tujuan], kemudian dicari fakta dari aturan-aturan yang memiliki tujuan tersebut sebagai kesimpulannya. Proses berlanjut sampai semua kemungkinan ditemukan. Metode ini dapat dilihat pada gambar 3 .

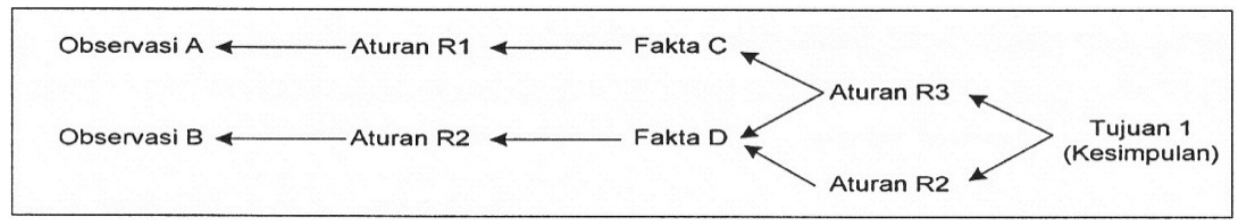

Gambar 3. Metode backward chaining

(Sumber: Perwira dan Azis, 2013:66)

\section{Metode Penelitian}

Jenis penelitian ini adalah penelitian deskriptif yang dilakukan dengan metode kualitatif. Tipe penelitian ini yang digunakan berdasarkan sifatnya merupakan penelitian Rekayasa Perangkat Lunak, yaitu dengan merancang dan membangun sistem pakar untuk mendiagnosa 
kerusakan perangkat televisi menggunakan metode backward chaining, yang dirancang dan dibangun menggunakan bahasa pemrograman Delphi XE3.

Objek pada penelitian ini adalah teknisi elektronika khususnya teknisi perbaikan kerusakan perangkat televisi. Tempat melakukan penelitian ini yaitu pada Laboratorium Listrik Dasar dan Pengukuran Jurusan Teknik Elektro Fakultas Teknik Universitas Tadulako yang berlokasi di Kota Palu Provinsi Sulawesi Tengah. Penelitian ini dilakukan mulai dari bulan Juli sampai dengan bulan September tahun 2014.

Berdasarkan sumbernya ada dua jenis sumber data yaitu data primer dan data sekunder. Data primer pada penelitian ini diperoleh secara langsung dari informan yang dijadikan sampel penelitian melalui wawancara mengenai hal-hal yang berkaitan dengan variabel penelitian. Misalnya: jenis kerusakan, ciri kerusakan, serta hal-hal yang berhubungan dengan perbaikan kerusakan perangkat televisi. Sumber data sekunder diperoleh dari literatur seperti buku-buku, internet, artikel atau jurnal ilmiah yang berhubungan dengan masalah penelitian.

\subsection{Tahapan Penelitian}

Penelitian ini dilakukan melalui tahapan-tahapan sebagai berikut:

a. Perumusan dan pengidentifikasian masalah

Pada tahap awal ini yang dilakukan merumuskan dan mengidentifikasi permasalahan yang ditemukan dari hasil observasi.

b. Pengumpulan data

Pada tahapan pengumpulan data ini, ada dua jenis data yang dibutuhkan, yaitu data primer dan data sekunder. Data yang terkumpul merupakan sumber informasi dalam perancangan dan pembangunan sistem pakar ini. Data yang diperoleh tersebut antara lain: data mengenai peralatan yang diperlukan untuk memperbaiki kerusakan perangkat televisi, data jenis-jenis dan ciri-ciri kerusakan perangkat televisi serta cara memperbaikinya, data cara perawatan perangkat televisi yang benar, dan data sejumlah teori yang digunakan sebagai pendukung penelitian ini.

c. Analisa data

Data primer yang dikumpulkan dari hasil wawancara langsung merupakan data mentah. Agar data tersebut dapat berguna bagi penelitian ini dibutuhkan suatu penyajian dan analisa data.

d. Perancangan dan pembangunan sistem pakar

Melakukan perancangan dan pembangunan fisik seperti perancangan dan pembangunan interface, database, dan pengkodean (coding).

e. Input basis pengetahuan

Pada tahap ini yang dilakukan adalah memasukan pengetahuan teknisi perbaikan kerusakan perangkat televisi (pakar) ke dalam basis pengetahuan sistem pakar.

f. Pengujian dan pengamatan

Pada tahap ini dilakukan ujicoba dan pengamatan pada sistem pakar yang telah dirancang dan dibangun, apakah sudah berjalan sesuai yang diharapkan atau belum.

g. Kesimpulan penelitian

Berdasarkan hasil pengujian dan pengamatan, diambil kesimpulan akhir penelitian ini.

Tahapan-tahapan penelitian ini dapat digambarkan dalam diagram alir pada gambar 4. 


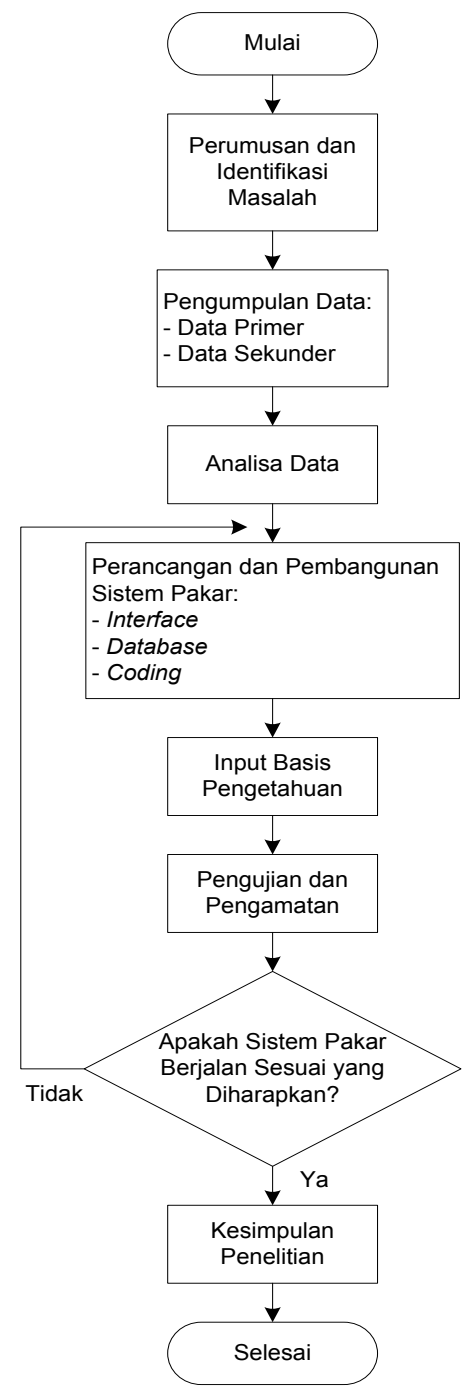

Gambar 4. Diagram alir tahapan penelitian

\subsection{Analisa Data}

\subsubsection{Diagram Konteks}

Proses perancangan pada penelitian ini dimulai dengan pembuatan DFD (Data Flow Diagram) level 0 atau yang dikenal dengan nama diagram konteks. Diagram konteks penelitian ini dapat dilihat pada gambar 5 .

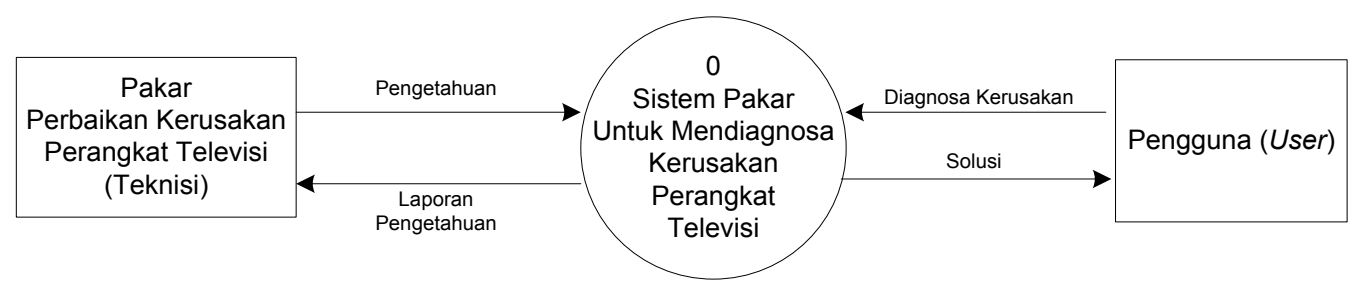

Gambar 5. Diagram konteks sistem pakar untuk mendiagnosa kerusakan perangkat televisi menggunakan metode backward chaining 


\subsubsection{Desain Database}

Sistem pakar ini dirancang dan dibangun menggunakan bahasa pemrograman Delphi XE3 dan Microsoft Office Acces 2010 sebagai database-nya. Sistem pakar ini mengggunakan empat buah tabel pada database yaitu:

Tabel 1.

Tabel DataUser

\begin{tabular}{|l|c|}
\hline \multicolumn{1}{|c|}{ Field } & Atribut (Size) \\
\hline userid & Text (15) \\
\hline password & Text (15) \\
\hline
\end{tabular}

Tabel 2.

Tabel DataCiri

\begin{tabular}{|l|c|}
\hline \multicolumn{1}{|c|}{ Field } & Atribut (Size) \\
\hline nociri & Text (4) \\
\hline nojenis & Text (4) \\
\hline ciri & Text (75) \\
\hline diagnosa & Memo \\
\hline
\end{tabular}

Tabel 3 .

Tabel DataJenis

\begin{tabular}{|l|c|}
\hline \multicolumn{1}{|c|}{ Field } & Atribut (Size) \\
\hline nojenis & Text (4) \\
\hline jenis & Text (75) \\
\hline gejala & Memo \\
\hline
\end{tabular}

Tabel 4.

Tabel Datapass

\begin{tabular}{|c|c|}
\hline Field & Atribut (Size) \\
\hline namapass & Text (15) \\
\hline
\end{tabular}

\subsubsection{Aliran Proses Sistem Pakar}

Aliran proses sistem pakar ini digambarkan dengan diagram alir menu sistem pakar pada gambar 6 dan diagram alir proses kerja sistem pakar berdasarkan hasil representasi pengetahuan yang disimpan dalam basis pengetahuan pada gambar 7 . 


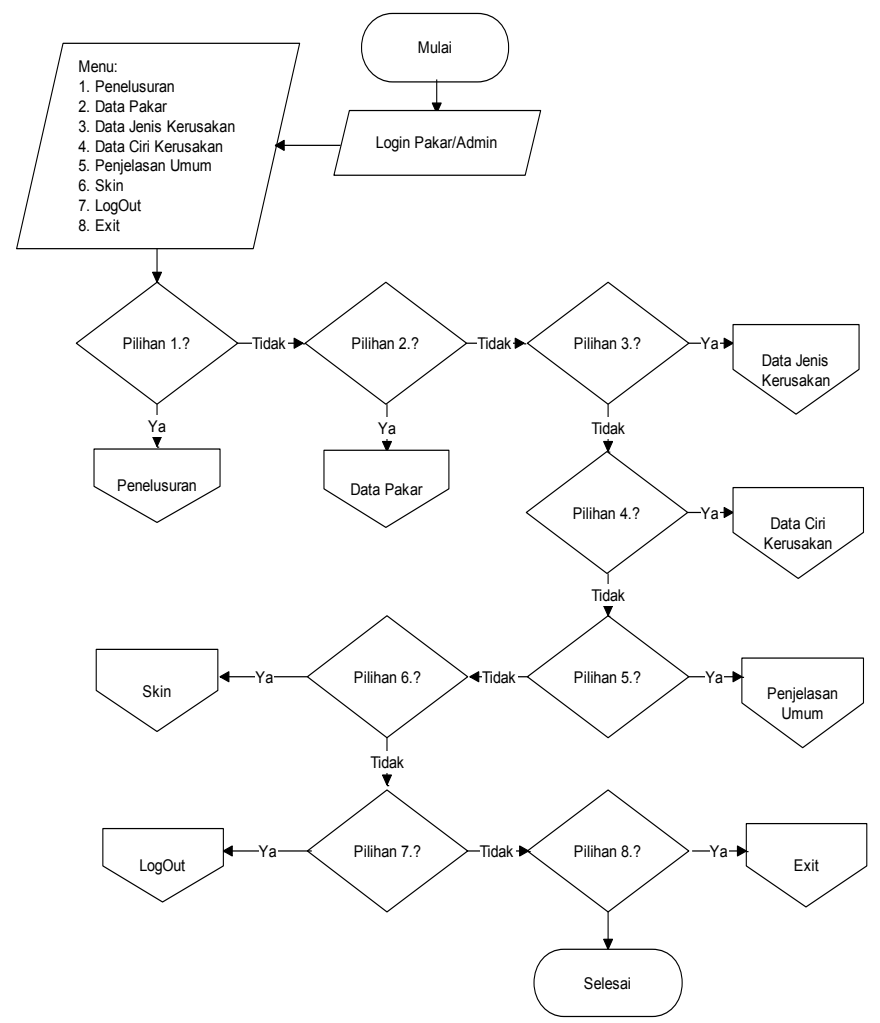

Gambar 6. Diagram alir menu sistem pakar

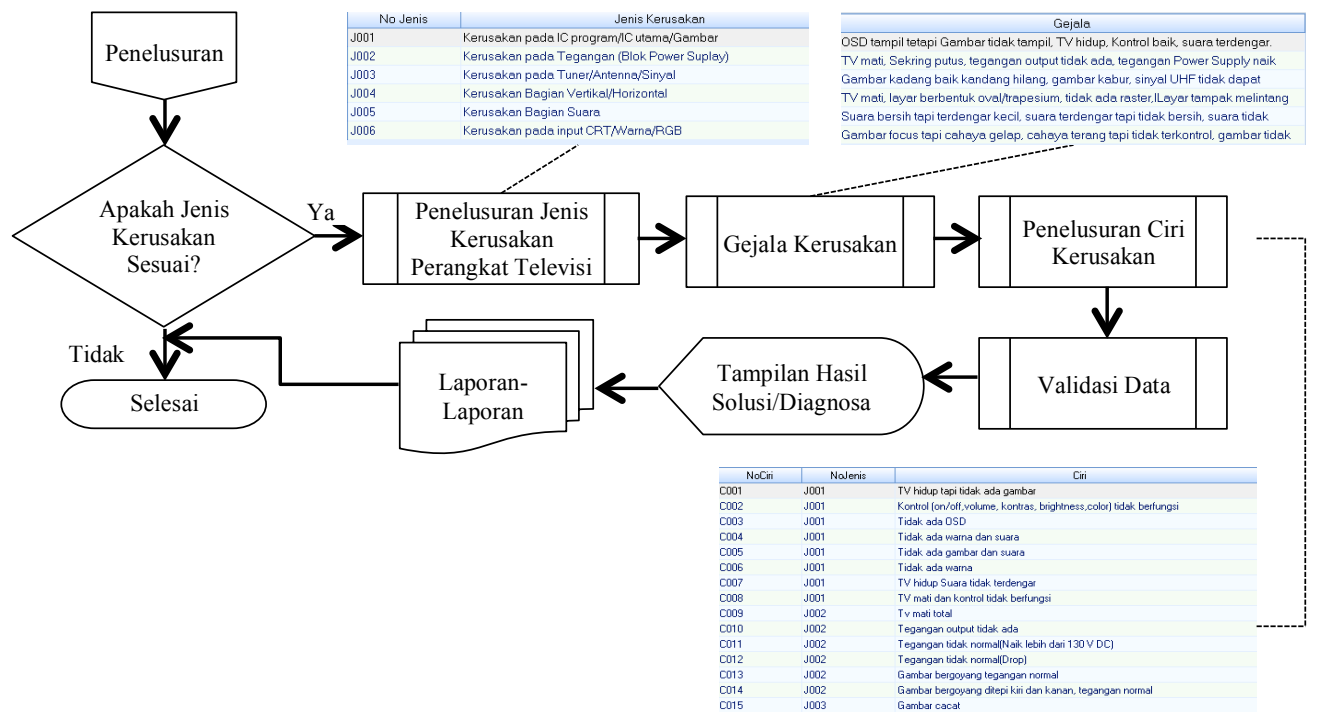

Gambar 7. Diagram alir proses kerja sistem pakar

berdasarkan hasil representasi pengetahuan yang disimpan dalam basis pengetahuan

\section{Hasil dan Pembahasan}

\subsection{Implementasi Sistem}

Secara sederhana, implementasi dapat diartikan sebagai suatu pelaksanaan atau penerapan. Dalam kaitannya dengan sistem pakar ini, implementasi sistem berarti menerapkan sistem yang telah dirancang dan dibangun untuk dilakukan uji coba dan dianalisa sejauh mana sistem berhasil sesuai dengan tujuan yang ingin dicapai. 
Sistem pakar ini diimplementasikan pada spesifikasi perangkat keras dan perangkat lunak sebagai berikut:
a. Personal Computer (PC)/Laptop dengan Processor Intel(R) Atom(TM) CPU N550@ $1.50 \mathrm{GHz}$.
b. Random Access Memory (RAM) 1 GB.
c. Hardisk kapasitas 160 GB.
d. Sistem Operasi Microsoft Windows 7 Ultimate.
e. Bahasa pemrograman Delphi XE3.
f. Microsoft Office Access 2010.

\subsection{Implementasi Interface (Antarmuka)}

Sistem pakar untuk mendiagnosa kerusakan perangkat televisi menggunakan metode backward chaining yang telah dirancang dan dibangun ini memiliki beberapa form yang memiliki fungsinya masing-masing. Form-form tersebut akan tampil sesuai menu yang dipilih.

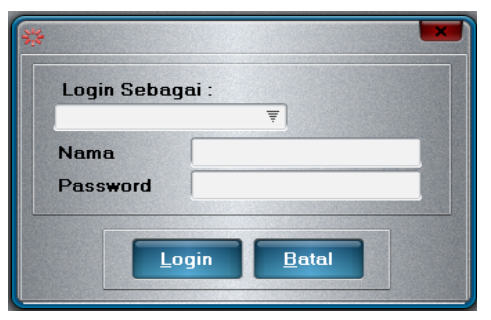

Gambar 8. Tampilan menu login

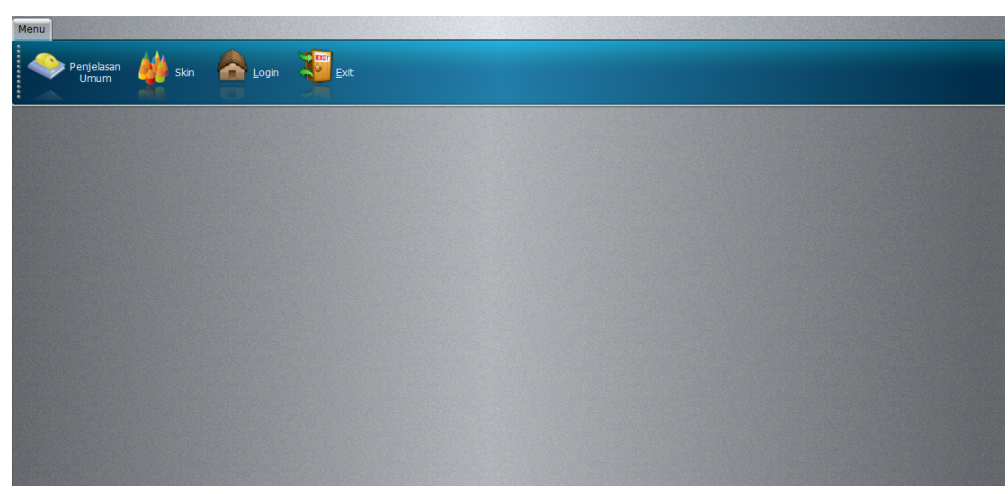

Gambar 9. Tampilan menu utama

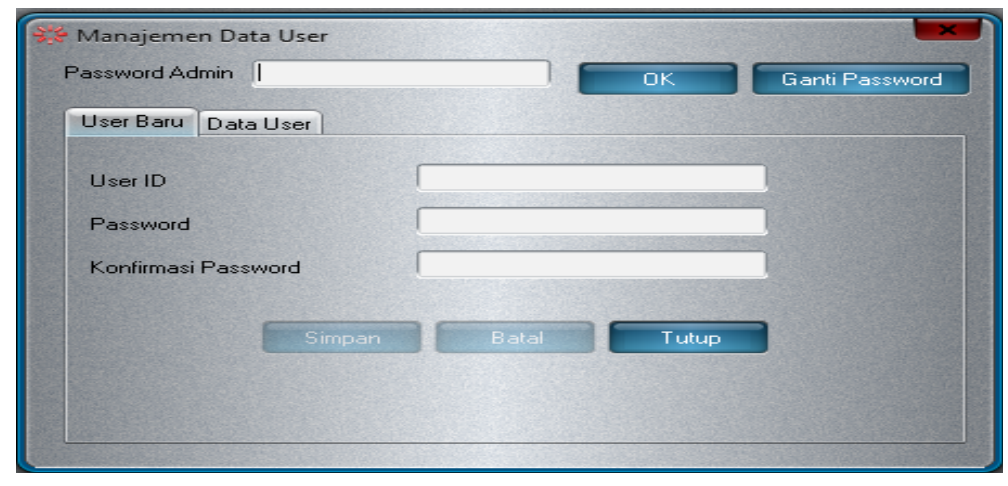

Gambar 10. Tampilan menu data user 


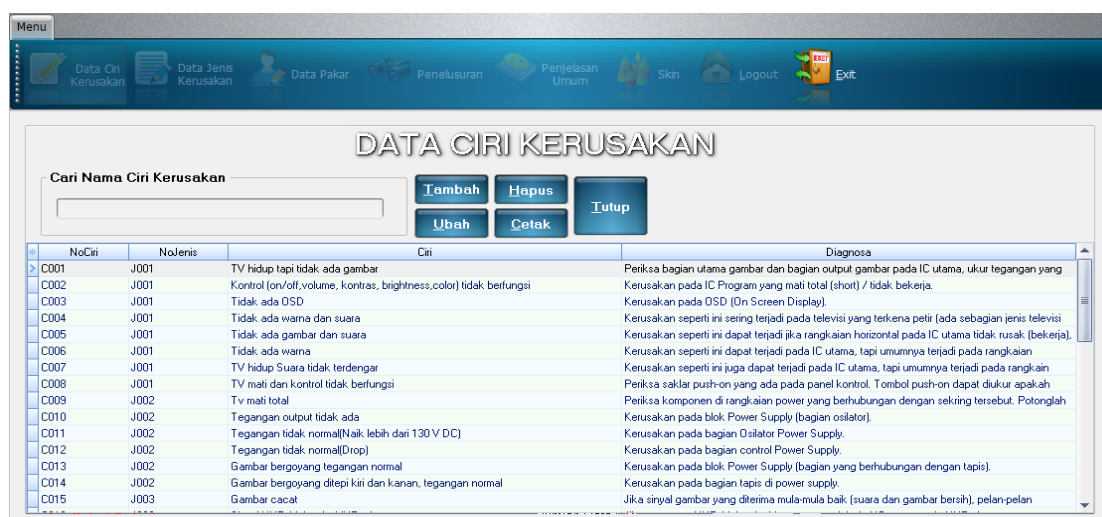

Gambar 11. Tampilan menu data ciri kerusakan

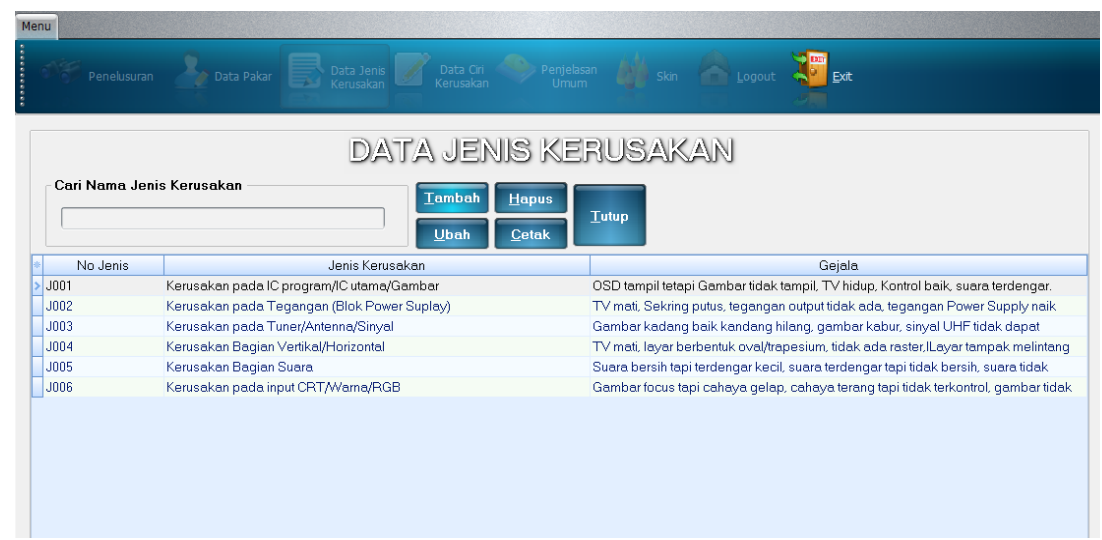

Gambar 12. Tampilan menu data jenis kerusakan

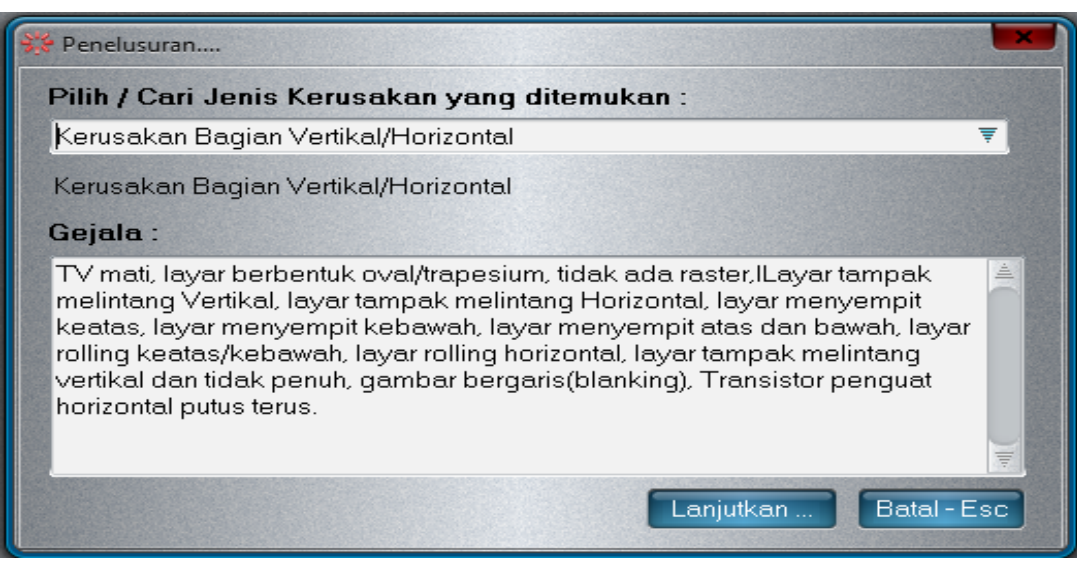

Gambar 13. Tampilan menu penelusuran jenis kerusakan

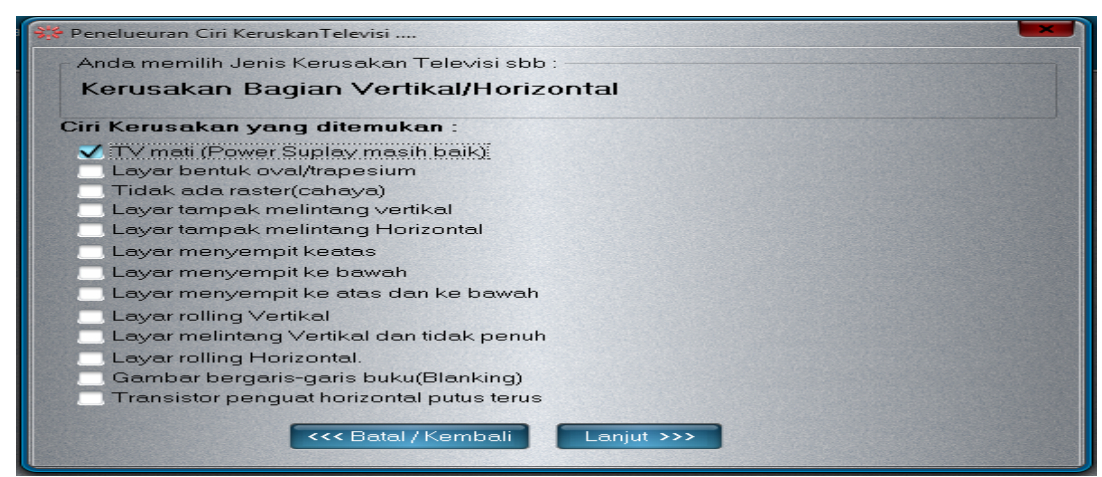


Gambar 14. Tampilan menu penelusuran ciri kerusakan

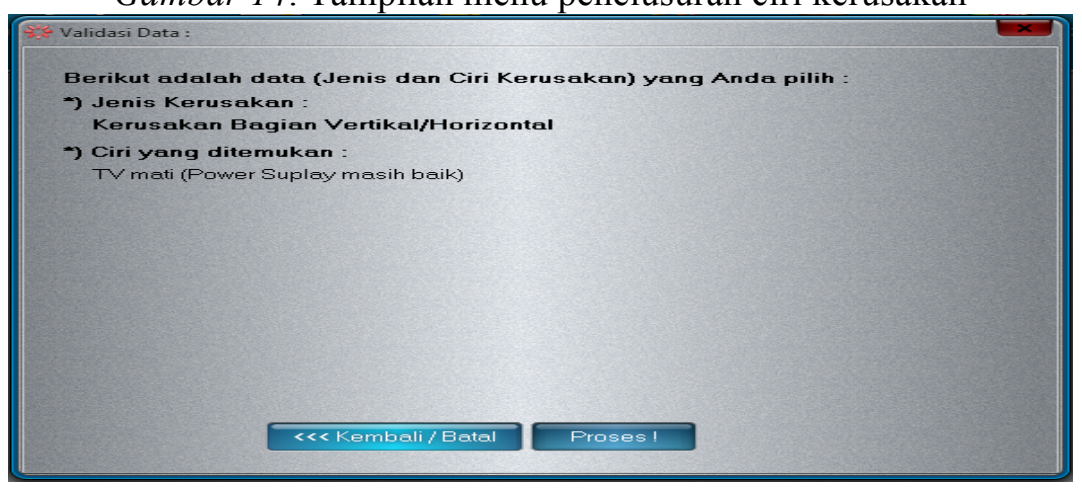

Gambar 15. Tampilan menu validasi data

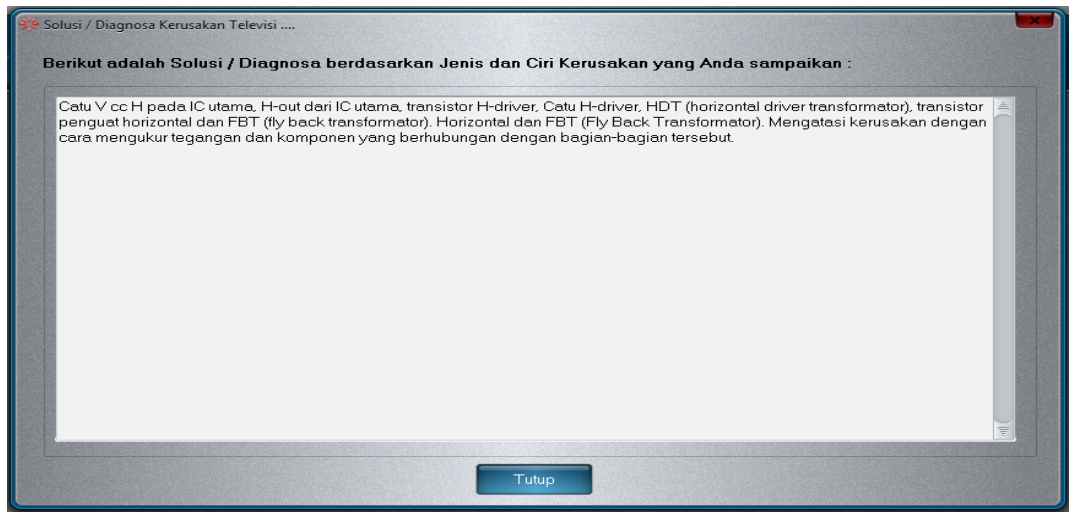

Gambar 16. Tampilan hasil solusi/diagnosa

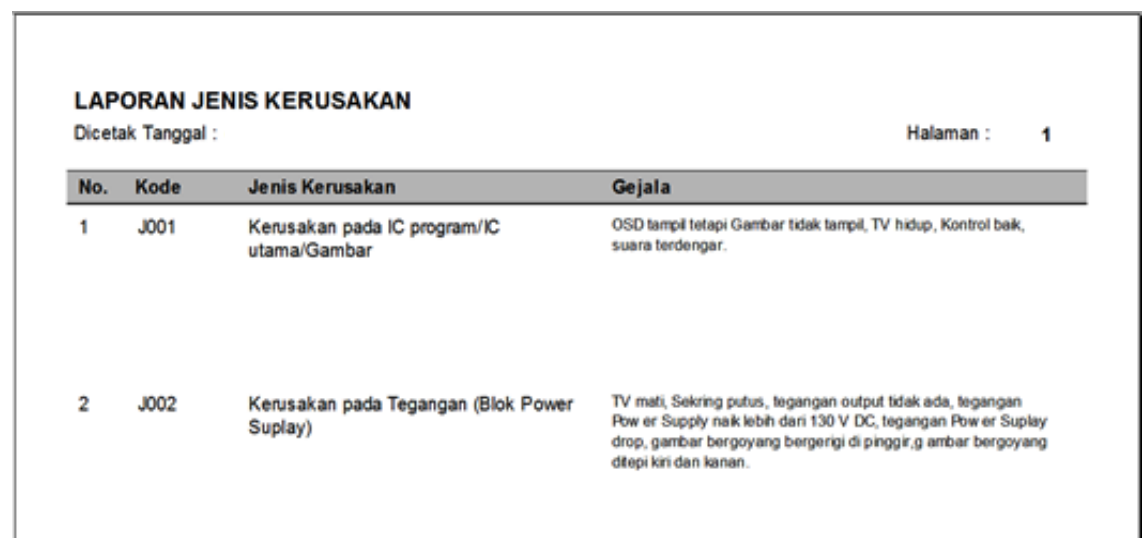

Gambar 17. Tampilan laporan jenis kerusakan 


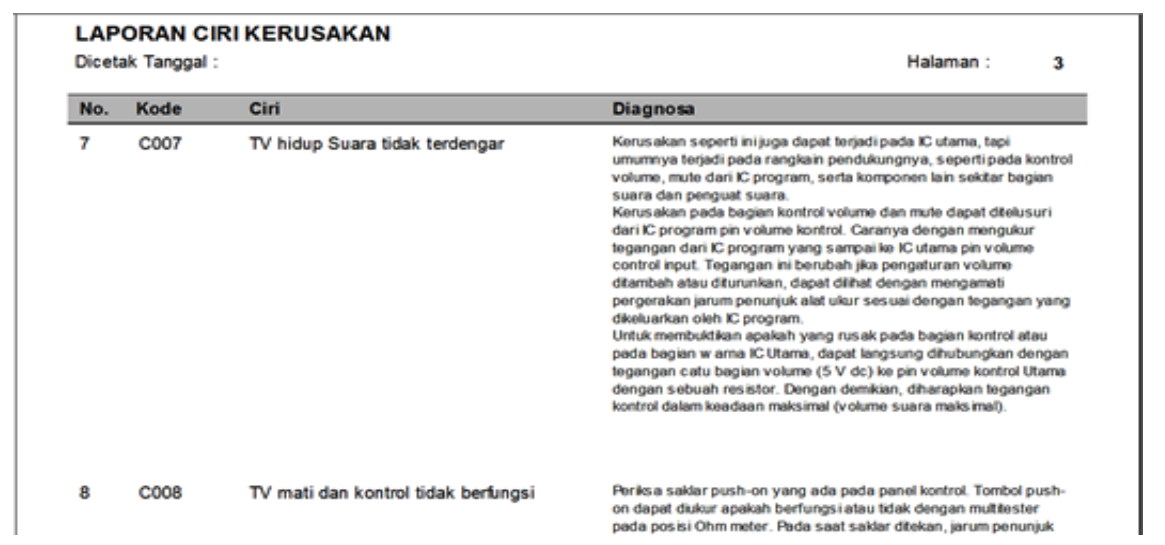

Gambar 18. Tampilan laporan ciri kerusakan

\subsection{Kemampuan Sistem Pakar}

Sistem pakar untuk mendiagnosa kerusakan perangkat televisi menggunakan metode backward chaining yang telah dirancang dan dibangun ini memiliki beberapa kemampuan sebagai berikut:

a. Memiliki fasilitas login pengguna yang dapat dibedakan sebagai pengguna biasa dan sebagai pengguna administrator atau pakar.

b. Tampilan menu utama sistem pakar ini dapat disesuaikan berdasarkan login pengguna.

c. Memiliki fasilitas untuk menambah pengguna baru yang dapat menggunakan sistem pakar ini dan memiliki fasilitas mengubah data pengguna lama yang telah tersimpan sebelumnya.

d. Sistem ini dapat memperlihatkan semua jenis kerusakan perangkat televisi beserta dengan gejala-gejala kerusakan perangkat televisi yang sesuai dengan jenis kerusakan tersebut.

e. Memiliki menu data ciri kerusakan perangkat televisi sesuai dengan jenis-jenis kerusakan perangkat televisi yang ada berdasarkan data masukan dari pakar perbaikan perangkat televisi. Data ciri kerusakan perangkat televisi ini beserta hasil solusi/diagnosanya dapat dengan mudah ditambahkan atau dapat dengan mudah diubah sesuai masukan dari pakar tersebut.

f. Sistem ini dapat melakukan penelusuran berdasarkan jenis kerusakan perangkat televisi yang dimasukkan/dipilih oleh pengguna, yang kemudian akan menampilkan semua ciri-ciri kerusakan berdasarkan jenis kerusakan tersebut, yang pada akhirnya akan menghasilkan solusi atau diagnosa perbaikan perangkat televisi secara lengkap berdasarkan jenis dan ciri kerusakan perangkat televisi yang dimasukkan/dipilih oleh pengguna.

g. Sistem ini dapat menghasilkan laporan jenis kerusakan dan laporan ciri kerusakan perangkat televisi.

Sistem pakar ini bekerja dimulai dengan seorang pengguna sistem pakar ini melakukan penelusuran jenis kerusakan pada perangkat televisi (gambar 13). Pengguna harus memilih salah satu jenis kerusakan perangkat televisi yang disediakan pada sistem pakar ini, dimana jenis kerusakan yang dipilih tersebut merupakan hasil kesimpulan awal yang akan dibuktikan kebenarannya. Jenis kerusakan yang dipilih tersebut merupakan hasil pengamatan langsung pengguna terhadap kondisi perangkat televisi sebenarnya. Pengguna sistem pakar ini harus sudah paham terhadap jenis-jenis kerusakan perangkat televisi tersebut.

Berdasarkan jenis kerusakan perangkat televisi tersebut, pengguna sistem pakar ini akan diperlihatkan gejala-gejala berdasarkan jenis kerusakan yang telah dipilih sebelumnya. Jika gejala tersebut cocok atau sesuai dengan kerusakan perangkat televisi sebenarnya, maka pengguna dapat melanjutkan penelusuran ke langkah selanjutnya. Langkah selanjutnya yaitu sistem pakar ini akan memperlihatkan semua ciri kerusakan perangkat televisi berdasarkan jenis kerusakan tersebut (gambar 14). Ciri-ciri kerusakan tersebut dapat dipilih oleh pengguna sesuai dengan kondisi kerusakan perangkat televisi yang akan diperbaiki. Ciri-ciri kerusakan tersebut berisi fakta-fakta yang mendukung jenis kerusakan yang telah dipilih sebelumnya. 
Selanjutnya sistem pakar ini akan melakukan validasi data (gambar 15) sesuai dengan jenis dan ciri kerusakan perangkat televisi yang telah dipilih sebelumnya. Hasil akhir sistem pakar ini adalah dapat memperlihatkan hasil diagnosa berupa aturan-aturan dan solusi perbaikan yang dapat dilakukan pengguna untuk memperbaiki kerusakan perangkat televisi yang meliputi aturan tentang komponen-komponen elektronika yang digunakan yang kemungkinan mengalami kerusakan, cara pengukuran komponen-komponen tersebut, dan cara mengatasi kerusakan perangkat televisi (gambar 16).

Kesimpulannya sangat jelas sistem pakar ini menggunakan metode backward chaining, karena dimulai dari sesuatu yang ingin dibuktikan yang merupakan kesimpulan awal berdasarkan hasil pengamatan langsung pengguna terhadap jenis kerusakan perangkat televisi yang akan diperbaiki dan hasilnya memperlihatkan fakta-fakta dan aturan-aturan yang sesuai dengan jenis dan ciri kerusakan perangkat televisi.

Sistem pakar yang telah dirancang dan dibangun ini terbukti mampu menerima, menyimpan, dan memindahkan pengetahuan dari pakar atau teknisi perbaikan kerusakan perangkat televisi yang sesuai dengan jenis dan ciri kerusakan perangkat televisi sebenarnya. Sistem pakar ini juga terbukti mampu berfungsi dengan baik untuk mendiagnosa kerusakan pada perangkat televisi berdasarkan jenis dan ciri kerusakan yang ada.

\section{Kesimpulan}

Berdasarkan hasil penelitian yang telah dilakukan, maka dapat diambil kesimpulan sebagai berikut:

a. Sistem pakar yang telah dirancang dan dibangun pada penelitian ini menggunakan metode backward chaining, karena dimulai dari sesuatu yang ingin dibuktikan yang merupakan kesimpulan awal berdasarkan hasil pengamatan langsung pengguna terhadap jenis kerusakan perangkat televisi yang akan diperbaiki dan hasilnya memperlihatkan fakta-fakta dan aturanaturan yang sesuai dengan jenis dan ciri kerusakan perangkat televisi.

b. Sistem pakar yang telah dirancang dan dibangun ini terbukti mampu menerima, menyimpan, dan memindahkan pengetahuan dari pakar atau teknisi perbaikan kerusakan perangkat televisi yang sesuai dengan jenis dan ciri kerusakan perangkat televisi sebenarnya. Sistem pakar ini juga terbukti mampu berfungsi dengan baik untuk mendiagnosa kerusakan pada perangkat televisi berdasarkan jenis dan ciri kerusakan yang ada.

c. Sistem pakar yang telah dirancang dan dibangun ini memiliki fasilitas-fasilitas antara lain: fasilitas login pengguna, tampilan menu utama yang dapat disesuaikan berdasarkan login pengguna, fasilitas untuk menambah pengguna baru, fasilitas untuk mengubah data pengguna lama, dapat memperlihatkan semua jenis kerusakan perangkat televisi beserta dengan gejala-gejala kerusakan perangkat televisi yang sesuai, memiliki menu data ciri kerusakan perangkat televisi, dapat melakukan penelusuran berdasarkan jenis dan ciri kerusakan perangkat televisi, menghasilkan solusi atau diagnosa perbaikan perangkat televisi secara lengkap, dan dapat menghasilkan laporan jenis kerusakan dan laporan ciri kerusakan perangkat televisi.

Adapun saran dari peneliti adalah dalam perancangan dan pembangunan sistem pakar ini, kehandalan sistem tergantung pada keakuratan dan kelengkapan data yang dimasukkan ke dalam sistem. Oleh karena itu, peneliti menyarankan untuk pengembangan selanjutnya sistem pakar ini, data yang diperoleh merupakan hasil wawancara langsung dengan beberapa pakar. Bila hanya berasal dari buku-buku, maka tidak dapat diambil pengetahuan dan pengalaman pakar-pakar tersebut yang tidak terdapat dalam buku-buku tersebut.

\section{Daftar Pustaka}

Desiani, A., Arhami, M. 2006. Konsep Kecerdasan Buatan, Penerbit CV. Andi Offset, Yogyakarta. Firmansyah. 2009. Sistem Pakar Diagnosis Kerusakan Pada Televisi Berwarna. Tugas Akhir Jurusan Ilmu Komputer, Universitas Siliwangi Jawa Barat, Tasikmalaya.

Hartati, S., Iswanti, S. 2008. Sistem Pakar dan Pengembangannya, Edisi Pertama, Penerbit Graha Ilmu, Yogyakarta. 
Kadir, A. 2014. Pengenalan Sistem Informasi Edisi Revisi, Penerbit CV. Andi Offset, Yogyakarta. Kusrini. 2006. Sistem Pakar, Teori dan Aplikasi, Penerbit CV. Andi Offset, Yogyakarta.

Lumbantobing, D. J. 2011. Aplikasi Sistem Pakar Diagnosis Kerusakan Pada Televisi Berwarna, Tugas Akhir Program Studi D3 Teknik Informatika, Fakultas Matematika dan Ilmu Pengetahuan Alam, Universitas Sumatera Utara, Medan.

Perwira, R. I, Aziz, A. 2013. Sistem Pakar Untuk Mendiagnosa Penyakit Infeksi TBC Paru, Jurnal Informatika dan Teknologi Informasi TELEMATIKA, Volume 9, Nomor 2, Januari 2013, Jurusan Teknik Informatika Fakultas Teknologi Industri Universitas Pembangunan Nasional "Veteran", Yogyakarta.

Priyono, A., Rahmat, R. A. O. K. 2013. Application of Artificial Intelligent for Urban Traffic Control System, Penerbit Mitra Wacana Media, Jakarta.

Rapu, F. S. 2012. Sistem Pakar Diagnosa Kerusakan Pesawat Televisi Berwarna Dengan Menggunakan Metode Forward Chaining, Skripsi Jurusan Teknik Informatika, Sekolah Tinggi Manajemen Informatika dan Komputer (STMIK) Bina Mulia, Palu.

Setiawan, H. T. 2011. Sistem Pakar Diagnosis Kerusakan Pada Televisi Berwarna, Skripsi Fakultas Teknologi Industri, Universitas Pembangunan Nasional "Veteran” Jawa Timur, Surabaya.

Suyanto. 2014. Artificial Intelligence: Searching, Reasoning, Planning, dan Learning, Revisi Kedua, Penerbit Informatika, Bandung. 